\title{
LOS HECHOS y su Interpretación
}

\author{
JUAN PADILLA MORENO \\ Universidad a Distancia de Madrid \\ Madrid | España \\ juan.padilla@udima.es
}

Se trata de arrojar claridad sobre la cuestión de la relación entre los hechos históricos y sus interpretaciones. Se mantiene la tesis de que unos y otras no pueden ni separarse ni confundirse porque son correlativos: su sentido depende de la relación que mantienen entre sí. Dicha correlación se puede observar incluso en el aspecto ético. Se ilustra la tesis con algunos ejemplos.

Hechos e interpretaciones - Interpretaciones históricas Historiografía y valoración ética 


\title{
THE FACTS and its interpretation
}

\author{
JUAN PADILLA MORENO \\ Universidad a Distancia de Madrid \\ Madrid | Spain \\ juan.padilla@udima.es
}

This paper tries to cast light on the relation between historical facts and their interpretations. The thesis maintained is that facts and interpretations are inseparable but at the same time can't be mixed up, because they are correlative: the sense of both terms depends on their mutual relation. This correlation can be observed even in the ethical aspects of history. The thesis is illustrated with some examples.

Facts and interpretations - Historical interpretations History and ethical assessment 
¿Es verdad que los hechos son inseparables de sus interpretaciones? O, como dice Nietzsche, ¿que lo único que hay en realidad son interpretaciones? El problema de la relación entre hechos e interpretaciones se ha planteado de manera recurrente en las ciencias humanas, en particular en la historia, sin que haya podido nunca resolverse enteramente. Sin embargo, no es un problema exclusivo de ellas: también las ciencias naturales se lo plantean. Fue el positivismo decimonónico sobre todo el que trazó una línea divisoria neta entre unos y otras, hechos e interpretaciones, y formuló un plan de trabajo que prescribía la determinación y recopilación de los hechos (los datos positivos) como condición previa para la elaboración de cualquier teoría. Teoría que para los positivistas debía adoptar siempre la forma de una ley general formulable por vía inductiva, tal como Stuart Mill describía en su Lógica ${ }^{1}$. Según esto, los hechos serían independientes de, y previos a, toda interpretación teórica.

La cuestión parecía definitivamente zanjada para todas las ciencias, y la historiografía (que aspiraba como la que más a serlo) lanzó a sus ejércitos de documentalistas a la tarea, titánica y cómoda a la vez ${ }^{2}$, de determinar exactamente los hechos, cuantos más mejor (es la época de las grandes colecciones documentales, iniciadas en 1826 con la benemérita Monumenta Germaniae historica), con la pretensión de servirlos crudos, en bruto, como ingredientes o materiales para posteriores elaboraciones. Las palabras de Ranke (sobre las que luego volveremos): ...wie es eigentlich gewesen, ("mostrar lo realmente ocurrido", "cómo ocurrieron los hechos"), convertidas en ideal de objetividad de toda una época, han quedado como expresión proverbial de esta tarea. Pronto empezaría a verse, sin embargo, que las supuestas leyes generales de la historia, derivadas de la inducción, no acababan de formularse y el mismo relato de los hechos no podía ser todo lo objetivo que se pretendía. Más aún: las mismas ciencias naturales empezaron a cuestionarse que los hechos directamente observables fueran, como se decía, un punto de partida absoluto, previo a la teoría e independiente de ella.

El resquebrajamiento del paradigma mecanicista en la física a finales del siglo XIX empezó a poner de manifiesto hasta qué punto los mismos hechos "observables" están insertos en modelos o teorías que se dan por supuestas y que son las que permiten verdaderamente la observación. El descubrimiento condujo a posiciones "convencionalistas" extremas, como la del matemático Édouard Le Roy (1870-1954), quien afirmaba que son los científicos los que crean los "hechos científicos". Frente a él, el también matemático Henri Poincaré (1854-1912) tendrá que puntualizar en La valeur de la science (1905) que lo que crean los científicos es el lenguaje para describir los hechos, no los hechos mismos. Y poco después el físico Pierre Duhem (1861-1916) mostrará que no hay "experimentos decisivos", como afirmaba Francis Bacon, que un hecho no

1 "Un determinado hecho tiene lugar invariablemente cuando se dan determinadas circunstancias, y no tiene lugar cuando no se dan; lo mismo ocurre con otro hecho, etc. Con estos diferentes hilos de conexión entre partes del gran todo que llamamos naturaleza se teje inevitablemente una trama de conexiones que mantiene unido el todo. (...) A estas distintas uniformidades, una vez establecidas por lo que se considera una inducción suficiente, es a lo que llamamos en el lenguaje habitual leyes de la naturaleza": A system of logic, libro III, cap. IV, $\mathbb{1} 1$ (Mill 2002, 206)

${ }^{2}$ ¡Con cuánta razón habla Febvre del "culto laborioso, pero intelectualmente perezoso, del "hecho" practicado por la historiografía positivista! (Febvre 1992, V). 
puede invalidar sin más una teoría, porque los hechos y los experimentos solo adquieren sentido en el contexto de teorías que son complejas y que pueden adaptarse a los hechos "adversos" modificando alguna de las hipótesis auxiliares o supuestos que las integran. A esta doctrina epistemológica, retomada décadas después por W. V. Quine (1908-2000), se la conoce como "holismo confirmacional" porque sostiene que los hechos aislados (que son siempre compatibles con varias teorías o interpretaciones) no confirman ni falsan las teorías, sino que estas se confirman o falsan en conjunto, por su capacidad de ajuste a la experiencia. Para Quine, lo que "hay" no depende de la teoría, pero sí depende de ella lo que "se dice que hay". Luego vendría todo el debate sobre el papel de los "paradigmas" en la historia de la ciencia desencadenado por Thomas Kuhn (1922-1996) a partir de The structure of scientific revolutions (1962), que desmitificó definitivamente el papel de los hechos o experimentos en la ciencia e introdujo en ella la historia, integrando como un factor decisivo en la elaboración de la ciencia la confrontación y sucesión de modelos teóricos. Pero el primero en formular el problema con toda claridad fue Michael Polanyi (18911976), quien ya en 1958 afirmaba: "Las operaciones formales que dependen de un marco o interpretación no pueden demostrar una proposición a personas que dependen de otro marco. Sus defensores no pueden siquiera explicarse ante estas, porque antes tienen que enseñarles una nueva lengua, y nadie puede aprender una nueva lengua a menos que confíe previamente en que significa algo" (1974, 151).

Lo ocurrido en la historiografía ha sido paralelo a lo acontecido en la filosofía de la ciencia. A lo largo del siglo XX se fue viendo que, más aún que en las ciencias naturales, los hechos (que aquí no serán ya "experimentos" sino "datos históricos contrastados") son inseparables de los modelos teóricos o esquemas interpretativos desde los que se abordan. ¿Significa esto que en la historia no se pueden distinguir los hechos de las interpretaciones? ¿ O que, como afirmaba Nietzsche, no hay hechos: solo interpretaciones? Y si se pueden distinguir, ¿cuál es la línea de demarcación que los separa? ¿Qué relación hay entre ellos? A este respecto, lo más frecuente es encontrar ideas vagas y confusas. Y creo encontrar la razón de esta confusión en que se toman "hecho" e "interpretación" como dos conceptos independientes, cuando son en realidad términos correlativos, cuyo sentido radica justamente en su mutua referencia.

"Hecho" e "interpretación" son, en efecto, términos correlativos porque se exigen entre sí y no se entienden el uno sin el otro, como padre e hijo, derecha e izquierda o masculino y femenino. Hay hechos porque, y en la medida en que, hay interpretaciones, y viceversa. Como hay derecha porque, y en tanto que, hay izquierda, y viceversa. Todo hecho reclama una interpretación, si es que no la lleva ya implícita o incoada. Todo "haber" (darse o suceder) es un haber (darse o suceder) "algo", y todo "algo" tiene sentido en tanto que lo "hay", sea cual sea el modo de haberlo. Dicho de otro modo: no solo no puede existir un puro "haber" (o un mero suceso), sino que ni siquiera tiene sentido pensarlo. Y otro tanto cabe decir de ser "algo". Los puros hechos, los hechos brutos, no solo no existen, sino que son absurdos. No puede haber nada que no sea, en su mismo darse fáctico, interpretado "como algo". Otro tanto es menester decir de las interpretaciones, que siempre lo son "de algo", o sea de algún hecho. Michael Oakeshott apunta esta íntima interconexión cuando dice en Modes of experience: "Cada 'hecho' separado sigue siendo una hipótesis hasta que se determine el mundo todo de los hechos en el que está envuelto. Y ningún hecho individual puede considerarse históricamente verdadero, y al margen de toda posible transformación, mientras el mundo todo de los hechos no haya alcanzado una 
condición de coherencia estable. Es imposible, por ejemplo, 'fijar' un texto antes de empezar a interpretarlo. 'Fijar' un texto implica una interpretación; el texto es la interpretación y la interpretación es el texto" ". Lo que ocurre es que su idealismo le lleva luego a sostener, con un lenguaje sutil y ambiguo, que, por esta correlación entre hecho y teoría, la experiencia es "pensamiento", y lo real, necesariamente racional (Oakeshott 2015, 42ss).

En la correlación está implícita la relación; es decir, que "hecho" e "interpretación" son términos relativos, no absolutos: son funciones ad hoc. Lo que hoy es una interpretación puede mañana ser un hecho, basta que funcione como tal, que se tome como tal. Y lo que hoy es generalmente aceptado como hecho puede pasar mañana a ser una interpretación. En su libro An introduction to philosophy of history W. H. Walsh afirma: "No hay realmente distinción de principio entre un hecho y una teoría. Un hecho es simplemente una teoría que se ha impuesto, una teoría acerca de cuya fiabilidad no existen ya dudas serias" $(1977,77)$. Pero que toda teoría pueda llegar a ser hecho, y viceversa, no significa que hecho y teoría (o hecho e interpretación), como funciones, no sean claramente distintas e inconfundibles. Un hijo puede llegar a ser, o ser también, padre, y un padre, hijo; pero eso no significa que paternidad y filiación sean lo mismo. Hecho e interpretación nunca se confunden. Algo puede ser indistintamente hecho o interpretación, pero no puede funcionar como ambas cosas al mismo tiempo.

Pensemos en un acontecimiento histórico concreto. Por ejemplo, el asesinato de Carrero Blanco, el jefe del gobierno español, el 20 de diciembre de 1973 por la banda terrorista ETA. Se trata evidentemente de un hecho, bien atestiguado documentalmente. Como tal lo toman los historiadores y parten de él para sus interpretaciones: ¿cuál fue su intención? ¿formaba parte de una estrategia determinada de acoso y derribo del régimen franquista? ¿cuáles fueron las consecuencias políticas inmediatas? Etc. Todo esto serían aspectos de lo que podría llamarse la interpretación del hecho. Las interpretaciones, en principio, son discutibles y no siempre mutuamente excluyentes. Por ejemplo, las relativas a la intención inmediata de los asesinos. Repárese, sin embargo, en que el llamar al hecho "asesinato" supone ya una intención: la de matar; se está afirmando con ello que no fue un accidente; más aún: se está atribuyendo al hecho una calificación penal, con connotaciones morales (no digamos si incluimos en el hecho la designación "banda terrorista"). Llamarlo asesinato es por tanto interpretar un acontecimiento en un determinado sentido, y puede considerarse ya una interpretación del hecho que supuso su muerte violenta. Una vez probada la tesis criminal, esta interpretación pasaría normalmente a considerarse un hecho, un "hecho probado"; pero un hecho constituido, al fin y al cabo, por la interpretación cierta de otro hecho, el de la muerte de Carrero Blanco por una explosión en la mañana del 20 de diciembre en la calle Claudio Coello de Madrid.

\footnotetext{
${ }^{3}$ Oakeshott 2015, 87. En otro lugar dice también: "Una teoría no corresponde a un número determinado de hechos: consiste en esos hechos vistos en el marco de un todo unificado. Las teorías se convierten en hechos cuando se hacen más ciertas y se establecen; los hechos se convierten en teorías cuando se ven dentro de una relación más amplia que muestra más plenamente sus implicaciones. Lo que desde un punto de vista es un hecho es, desde otro, una teoría" $(2015,33)$.
} 
Cuando algo es seguro tendemos a decir que es un hecho, no una interpretación ${ }^{4}$. Las interpretaciones, en efecto, son a menudo discutibles. A veces, falsas. Hay algo forzado, en cambio, en decir de un hecho que es falso. Pero importa subrayar que al decir de algo que es una interpretación no estamos afirmando necesariamente que sea inseguro y opinable (o, como con frecuencia se dice, que las interpretaciones sean "subjetivas"); lo que estamos haciendo simplemente es, de una u otra forma (con más o menos conciencia), atribuir sentido a unos hechos susceptibles de tenerlo, que lo reclaman. ¿Por qué damos por supuesto que los hechos son sin más verdaderos, mientras que con frecuencia basta decir de algo que es una interpretación para poner en duda, o negar directamente, su verdad? ¿Por qué tendemos a decir de algo que "no es más que una interpretación”, o es una "mera interpretación”, mientras que no se nos ocurre decir de algo que es un "mero hecho", al menos con la intención de descalificarlo? Sea cual sea el uso espontáneo y coloquial de estas expresiones, lo cierto es que, en rigor, así como no hay meras interpretaciones (que no tengan al menos una referencia a la realidad, porque las interpretaciones siempre lo son de algo) tampoco hay meros hechos. Los hechos, o los datos, al ser aprehendidos, son sometidos siempre a una interpretación, por mínima que sea: son aprehendidos como algo; de lo contrario no podrían ser siquiera aprehendidos. Robinson Crusoe, observa Collingwood, "no establece primero que se trata de una huella humana y luego infiere que ha sido producida por un visitante humano. (...) Descubrir el indicio es ya interpretarlo. Al reconocerla como una huella, Crusoe ya ha sacado la conclusión de que ha habido un visitante" $(2001,140)$.

Esto, llevado al terreno específico de la historia, significa que entre crónica e historiografía hay, desde luego, diferencia, pero no una fractura

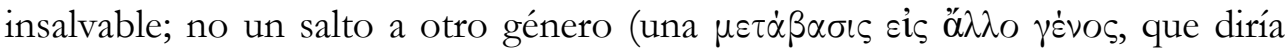
Aristóteles), sino una transición progresiva; porque toda crónica, más allá del registro y la descripción de los hechos, lleva ya incoada al menos una interpretación de los mismos. Es la tesis de Arthur C. Danto cuando critica la idea, frecuentemente repetida, de que los historiadores, además de hacer afirmaciones más o menos ciertas sobre el pasado, como hacen los cronistas, pretenden también interpretarlo, de modo que, "aunque tuviéramos un relato perfecto del pasado, quedaría por hacer la interpretación". Frente a esta distinción, Danto sostiene que "la historia es toda del mismo tipo (all of a piece). Es toda del mismo tipo en el sentido de que no hay nada que pueda denominarse una pura descripción en contraste con algo distinto que pueda denominarse interpretación" $(1965,115)$. Las palabras de Danto, que subrayan la continuidad, no implican sin embargo identidad entre crónica e historia, entre descripción e interpretación; porque se admiten evidentemente, como nosotros admitimos, diferencias de grado y complejidad en la interpretación. Es evidente que la descripción de una simple "crónica" medieval es menos completa, mucho más pobre que la aportada por la historiografía posterior, que va progresivamente enriqueciéndose, sin poder aspirar nunca a ser definitiva. "Describir por completo un suceso (event)", dice Danto, "es situarlo en todas las narraciones apropiadas, y esto es algo que no podemos hacer. No podemos porque somos temporalmente provincianos con respecto al futuro. No podemos por las

${ }^{4}$ La afirmación de hechos (salvo que se trate de una mentira) lleva siempre implícitos la adhesión y el asentimiento personales del hablante. El que afirma un hecho, por la misma dinámica del lenguaje, se compromete y se hace garante de lo que dice; incluso, sostiene Polanyi, del mismo significado de sus palabras $(1974,253$ ss $)$ 
mismas razones por las que no podemos realizar una filosofía especulativa de la historia" $(1965,142)$.

Uno de los aspectos más característicos de la interpretación de los hechos (aunque no sea el más importante ni, por supuesto, el único), donde esta se hace más evidente, es el de su valoración moral, a la que ya aludimos al hablar del asesinato de Carrero Blanco. En la valoración moral podría acaso verse una diferencia cualitativa respecto de la mera descripción o relato factual: la historia juzgaría mientras que la crónica se limitaría a registrar hechos o datos absteniéndose de toda valoración. El célebre verso de Schiller, "La historia universal es el juicio universal" (Die Weltgeschichte ist das Weltgericht), sería la mejor expresión de esta visión de la historia. Pero no fue esa la idea que se impuso a partir del primer tercio del siglo XIX, en el largo periodo positivista. El ideal es entonces el formulado por Ranke, modelo inspirador de la historiografía hasta por lo menos la Primera Guerra Mundial. Las palabras de Ranke a las que antes nos referíamos deben ser leídas en su contexto. La frase completa es: "Se ha atribuido a la historia la función de juzgar el pasado y de enseñar al mundo de cara a tiempos venideros; el presente ensayo no pretende asumir tan altas funciones: solo quiere mostrar lo realmente ocurrido" "La pretensión de contar "lo realmente ocurrido" no es, como a menudo se supone, una expresión de soberbia, sino al revés, de autolimitación y modestia. La famosa expresión de Ranke no quiere decir en rigor que la historia se arrogue un papel superior, capaz de dictaminar desde un supuesto empíreo, con suprema objetividad, lo realmente ocurrido, sino más bien lo contrario: que la historia es una humilde funcionaria notarial que debe limitarse a dejar constancia de los hechos sin juzgarlos ni pretender ser maestra del futuro ${ }^{7}$. Sin embargo, en el siglo XX vuelven a cambiar las tornas. Desde la escuela de los Annales, los historiadores empiezan a verse a sí mismos no como neutrales relatores, sino como agentes implicados en la historia, comprometidos con su objeto de estudio y con el presente. Y ya a finales de siglo, la historiografía "posmoderna" considerará la mera idea de un relato verídico de los hechos como una ilusión ingenua y pretenciosa; es entonces cuando la modestia de Ranke empieza a interpretarse como soberbia. De ser el modelo de toda una época pasa así a convertirse en blanco de todas las críticas.

Sea cual sea la valoración que nos merezcan la actitud de Ranke (la historiografía positivista en su conjunto) y las consabidas críticas que se le dirigen desde la historia posmoderna, la neutralidad axiológica es, simple y llanamente, imposible, ya desde los más elementales enunciados. Porque las valoraciones éticas no son algo que se construye al elegir las tramas narrativas y elaborar los "grandes relatos", sino que están implícitas en las mismas denominaciones y en las más simples atribuciones causales, sin las cuales, como observa agudamente Danto, no habría siquiera crónicas, porque estas no son nunca series de frases inconexas $(1965,117 \mathrm{ss})$. Hasta que los hechos no están insertos de alguna manera en una narración, que inevitablemente trata de explicar (aunque solo sea mostrando la sucesión de los acontecimientos) y, explícita o implícitamente,

${ }^{5}$ En el poema "Resignation", de 1786 (Schiller s.f., 160)

6"Man hat der Historie das Amt, die Vergangenheit zu richten, die Mitwelt zum Nutzen zukünftiger Jahre zu belehren, beigemessen: so hoher Ämter unterwindet sich gegenwärtiger Versuch nicht: er will blo $\beta$ zeigen, wie es eigentlich gewesen“: el texto apareció por primera vez en octubre de 1824, en el Prólogo a la primera edición de Geschichten der romanischen und germanischen Völker von 1494 bis 1514 (Ranke 1885, VII).

${ }^{7}$ Sobre el verdadero sentido de la fórmula rankeana wie es eigentlich gewesen cf Koselleck (1989, 55); Danto (1965, 130ss); y Fulbrook (2008, 13). 
atribuye responsabilidades, no pueden denominarse hechos históricos (Danto $1965,122)$.

Hay en esto de las valoraciones morales poca claridad, mucha inconsistencia y algo de hipocresía entre los historiadores. Por un lado, se critica el moralismo de la historiografía tradicional, que se entendía a sí misma como magistra vitae y dispensadora de justicia (justamente la visión que censuraba Ranke), y, por otro, se proclama sin ambages la necesidad de no ser neutral, de tomar partido ${ }^{8}$. Si se analiza un poco, se encuentra que lo que verdaderamente se censura es la emisión de determinados juicios morales, hoy considerados ingenuos o anticuados ${ }^{9}$, no la moralización, no el trasfondo ético de la labor historiográfica en cuanto tal. Reconózcalo o no, lo cierto es que el historiador no puede prescindir enteramente de las valoraciones morales, ni siquiera en la más elemental descripción de los hechos, por la sencilla razón de que dichas valoraciones están como incrustadas en el lenguaje, impregnando los términos que usamos ("guerra" y "paz", "cultura", "civilización" y "barbarie"; "desarrollo", "progreso", "involución"; "libertad" y "justicia”; "autoridad", "legitimidad", "opresión"; "ciencia", "filosofía", "racionalidad"; "santidad", "secularidad"; "organización" y "desorganización"; "dinamismo" y "estancamiento"; "decadencia" y "esplendor"; "nacionalismo", "colonialismo", "imperialismo", "emancipación”; “identidad", "pluralidad", "patriarcado"; etc., etc.). Y sin embargo... ¿quién puede negar que la labor historiográfica exige, al mismo tiempo que un compromiso ético, cierta dosis de objetividad, neutralidad, imparcialidad, llámese como se quiera? En este sentido, "la caracterización de Ranke, a pesar de su vaguedad y de las inverosímiles lecturas que han hecho de ella críticos poco comprensivos, es, como dice Danto, "una caracterización admirable de lo que los historiadores tratan de hacer" $(1965,139)^{10}$. Lo cierto es que el nivel de "compromiso", y la justeza y admisibilidad de las valoraciones (como de las interpretaciones en general), vienen dados por un consenso tácito de los historiadores, y dependen de las expectativas sociales y las creencias colectivas.

8 "Es moda en la actualidad solicitar de los historiadores que emitan un juicio moral" (Tucker 2011, 256).

${ }^{9}$ Valga, como ejemplo de los mismos, lo que escribe Voltaire en Essai sur les moeurs et l'esprit des nations (1756) sobre Felipe II: "La posteridad ha colocado a este príncipe entre los más poderosos, pero no entre los más grandes. Se le llamó Demonio del Mediodía, porque desde España, en el Mediodía de Europa, perturbó a todos los demás estados. Y si, tras haberlo considerado en el ámbito del gobierno, lo observamos en su vida privada, vemos en él a un amo duro y desconfiado, a un amante, a un marido cruel y a un padre despiadado": cap. CLXVI (Voltaire 1990, 463). O este otro texto, aún más elocuente, de Gibbon en The decline and fall of the Roman Empire (1776-89), a propósito de las persecuciones de los primeros cristianos: "La historia, cuya tarea es registrar los hechos del pasado para instrucción de edades futuras, no sería merecedora de su honrosa función si consintiera en ponerse del lado de los tiranos o en justificar las máximas de la persecución. Es menester reconocer, no obstante, que la conducta de los emperadores que se mostraron menos favorables a la Iglesia primitiva no fue, ni de lejos, tan criminal como la de los soberanos modernos que han empleado la violencia y el terror contra las opiniones religiosas de una parte de sus súbditos": cap. 16 (Gibbon 1998, 313).

10 Alguien que reconoce abiertamente este sesgo ético, si se puede decir así, es E. H. Carr: "Las interpretaciones históricas implican siempre juicios morales" (1990, 79). Aunque en la misma página se contradice a sí mismo afirmando: "El historiador debe emitir juicios morales sobre la institución, pero no sobre los individuos que la crearon" (1990, 79). Contradicciones al margen, se pregunta uno por qué. 
En tiempos recientes, la apelación a un lenguaje axiológicamente neutro por parte de los historiadores se ha planteado con frecuencia en el contexto del multiculturalismo y las críticas de los estudios poscoloniales a la historiografía occidental, que pretendería imponer su sistema de valores (progreso, libertad, secularidad, capitalismo, democracia, igualdad...) a los países de alguna manera colonizados o poscolonizados. "El método histórico, tal como es entendido de manera prácticamente universal en Occidente", dice Ermath, "se basa en el común denominador de los valores que caracterizan la modernidad. Los historiadores consideran estos valores como si fueran universalmente válidos y rara vez los confiesan" (Tucker 2011, 260). Sin duda. Pero si no lo hicieran así, si no consideraran dichos valores como dotados de validez general, no serían para ellos valores. Y desde luego, los historiadores no occidentales no pueden dejar de hacer lo mismo. Porque, en rigor, un valor privado es un contrasentido. $\mathrm{Si}$ es verdad que los historiadores occidentales pretenden imponer sus valores al resto de culturas (es decir, juzgarlas desde dichos valores), esto no es criticable desde una supuesta neutralidad axiológica, y en nombre de ella, sino desde otros valores, que habrá que especificar: los de cada pueblo o historiador; en el fondo, si son sinceros, con similares pretensiones de validez universal.

Esto, claro está, en el supuesto de que se siga aceptando la existencia de valores propiamente dichos; porque lo que hay detrás de gran parte del relativismo multicultural y posmoderno no es la afirmación de unos valores alternativos (supuestamente "construidos" por el sujeto o la comunidad cultural), sino la negación de todo valor. El valor, por esencia, ya lo hemos dicho, es siempre objetivo y se afirma como aspirante a validez universal: lo que valoramos es, fenomenológicamente, algo distinto de lo que nos gusta o nos conviene. Si todo valor o "discurso" es "ideológico", como parece darse por supuesto en muchos debates actuales, no hay ya valor ni verdad, sino simplemente lucha de poder; que es a lo que efectivamente parece reducido en muchos casos el debate historiográfico.

Y no se trata solo de las valoraciones éticas que, explícita o implícitamente, acompañan a las interpretaciones. La misma selección de los hechos históricos que se pretende interpretar (que, como hemos apuntado, a menudo solo son observables desde un marco interpretativo previo, pero que, como hechos, son siempre lógicamente previos a la interpretación) supone ya una escala de importancias por parte del historiador. La importancia es la primera categoría ética. Nada es objeto de la experiencia o el pensamiento, tanto en las ciencias humanas como en las ciencias en general, que no esté inserto, no ya en una red conceptual ${ }^{11}$, sino en una escala de importancia, diversamente graduada, por supuesto, según las intenciones y los proyectos. Sin importancia no hay hechos. Nada "es" si no "es relevante". En el simple atender y mirar va implícito el ver algo en lo que miramos y el considerarlo importante. El "ver algo" y el "dar importancia" son dos aspectos esenciales de la interpretación. Y como tales no se pueden confundir con los hechos mismos. Ni separar de ellos.

El primer capítulo (con diferencia el mejor) del enormemente leído e influyente libro de E. H. Carr What is history (1961) lleva por título "The historian and his facts". En él se describe la historia como una interacción continua entre hechos e interpretaciones: "El historiador está implicado en un proceso continuo de moldeado de sus hechos según su interpretación, y de su

11"La idea que nos hacemos de un objeto", dice Peter Winch, "no consiste solo en elementos tomados de la observación del objeto aislado, sino que incluye la idea de las conexiones entre este y otros objetos (y apenas puede concebirse un lenguaje en el que no sea asî)" $(1991,124)$. 
interpretación según sus hechos" (1990, 29). "El historiador", acaba diciendo el capítulo, "sin sus hechos carece de raíces y es vano; los hechos sin su historiador están muertos y carecen de sentido. Mi primera respuesta a la pregunta ¿qué es la historia? es que es un proceso continuo de interacción entre el historiador y sus hechos, un interminable diálogo entre el presente y el pasado" (1990, 30). Sin duda; lo que resulta más dudoso es que, según dice Carr, sea "imposible asignar la primacía a una [la interpretación] u otros [los hechos]" (1990, 29); porque, aunque en la práctica se parta muchas veces de la interpretación, desde un punto de vista lógico y epistemológico, el primado, como ya he dicho, pertenece a los hechos. La necesaria interpretación no anula ni invalida la función irreductible de los hechos: los hechos son precisamente lo irreductible de toda interpretación; aquello de que la interpretación no puede prescindir, si quiere seguir siendo interpretación, o sea aprehensión de algo en tanto que realidad, y no ficción o pura arbitrariedad.

Conviene prevenir un posible malentendido. Tiene razón Koselleck cuando advierte que los hechos mismos son extralingüísticos y no coinciden con su expresión, con lo que se dice de ellos o el modo en que se narran. "La realidad histórica", afirma, "nunca coincide con lo que lingüísticamente puede articularse en ella y sobre ella. La historia nunca se reduce a lenguaje. Nos encontramos en una tensión que no puede suprimirse y que impide que ningún acto lingüístico alcance jamás la realidad histórica. (...) La realidad histórica misma, sin embargo, solo se constituye entre, antes o después de las articulaciones lingüísticas que apuntan a ella. (...) La temporalidad de la historia no puede ser alcanzada por ningún acto lingüístico. (...) La historia nunca se realiza sin lenguaje, pero al mismo tiempo es siempre otra cosa: más o menos" (Koselleck 2014, 88ss) ${ }^{12}$. Los relatos históricos son una interpretación de los hechos, que no los agota y, al mismo tiempo, los rebasa. Esto es cierto. Es claro que una cosa son los hechos, y otra, lo que se dice de ellos; una cosa son los datos, y otra, como he mostrado, su interpretación. Pero no hay que olvidar que el decir también es un hacer. Por medio del lenguaje no solo se describen hechos o se expresan sentimientos y deseos, sino que, como explica Austin (1962), con las palabras también se hacen cosas: se dan órdenes, se hacen promesas, se condena a muerte o se piden disculpas. Es lo que Austin llama la función "performativa" (performative) o "ilocucionaria" (illocutionary), o sea ejecutiva, del lenguaje. Muchos hechos históricos son "actos de habla" en este sentido. Pero es que, además, hay que tener presente que las interpretaciones pueden ser puramente fácticas, extralingüísticas. Interpretar algo no significa necesariamente decir algo sobre ello. Simplemente con mi conducta, sin decir una palabra, puedo interpretar una piedra como asiento o (si soy forzudo) como arma arrojadiza ${ }^{13}$. Los mismos hechos, aunque sean "mudos", están en muchos casos cargados de sentido". Interpretación y lenguaje, por tanto, no se identifican.

\footnotetext{
${ }^{12} \mathrm{Y}$ en otro lugar: "Las historias extralingüísticas del mundo contienen siempre más o menos de lo que puede decirse sobre ellas lingüísticamente; y al contrario: en todo discurso anterior, simultáneo o posterior a una historia se dice sobre ella más o menos de lo que en efecto ocurre o ha ocurrido" (Koselleck 2014, 111).

${ }^{13}$ En La imagen de la vida humana (1956) Julián Marías muestra cómo lo que proyectamos con las cosas las configura como tales: "Esto es una mesa porque proyecto sobre ella apoyar los codos, poner un libro o un vaso encima; pero se convierte en leña ante el proyecto de hacerla arder en la chimenea; en balsa, como resto de un naufragio; en trinchera que me defiende de un agresor..." (Marías 1969, 534).

${ }^{14}$ Cf Droysen $(1974,361)$, y Carr $(1990,11)$.
} 
La correlación móvil, en fin, entre hechos e interpretaciones que hemos descrito es posible solo sobre la base de un lecho firme que da soporte a unos y otras, a hechos e interpretaciones, y sin el cual no es concebible la historia en ningún sentido, ni como historiografía ni como obrar humano. Es el subsuelo de las creencias. Por creencias no entiendo actos de fe explícitos, sino los supuestos implícitos en los que se basa a última hora, no solo el conocimiento, sino la técnica, el arte y el resto de actividades que configuran la vida humana. Son, como decía Ortega, aquello en lo que estamos: "las ideas se tienen, en las creencias se está"15. Con distintos matices y alcance, la misma convicción se encuentra también en Collingwood (1940). Y desde un punto de vista más gnoseológico que metafísico, está virtualmente contenida en los planteamientos de Polanyi (1974) cuando habla de la "dimensión tácita" y de Gadamer cuando pone de manifiesto la inevitabilidad de los "prejuicios" en el "círculo hermenéutico" (1990).

Son las "creencias", en este sentido, ciertamente, las que hacen posibles las interpretaciones. Pero también, aunque resulte paradójico, las que hacen posibles los hechos. No en sentido absoluto (porque no existen, según hemos visto, hechos absolutos), sino en tanto que hechos susceptibles de ser interpretados. Unos hechos que son, además, en la inmensa mayoría de los casos, colectivos. Solo la comunidad de creencias permite, no ya la coincidencia en las interpretaciones, sino la identificación de los hechos mismos. Por eso puede decirse, en definitiva, que las creencias (en las que no hay nada, lo advierto, de arbitrario) son la realidad o, lo que es lo mismo, funcionan como tal. Pero es este un tema cuyo desarrollo suficiente debemos dejar para otra ocasión.

\section{REFERENCIAS}

AUSTIN, J. L. How to Do Things with Words. Oxford / Nueva York: Oxford University Press, $1962^{2}$.

CARR, E. H. What is History. Penguin, 1990.

COLLINGWOOD, R. G. The Principles of History and Others Writings in Philosophy of History. Oxford: Oxford University Press, 2001.

COLLINGWOOD, R. G. An Essay on Metaphysics. Oxford: Clarendon Press, 1940.

DANTO, Arthur C. Analytical Philosophy of History. Cambridge: Cambridge University Press, 1965.

DROYSEN, Johann Gustav. Historik: Vorlesungen über Enzyklopädie und Methodologie der Geschichte. Darmstadt: Wissenschaftliche Buchgesellschaft, 1974.

FEBVRE, Lucien. Combats pour l'bistoire. París: Armand Colin, 1992.

FULBROOK, Mary. Historical Theory. Londres / Nueva York: Routledge, 2008.

GADAMER, Hans-Georg. Wabrheit und Methode: Gesammelte Werke, I. Tubinga: J. C. B. Mohr, 1990.

GIBBON, Edward. The History of the Decline and Fall of the Roman Empire. Ware (UK): Wordsworth, 1998.

15 Las creencias, escribe Ortega, "constituyen el continente de nuestra vida, y por ello, no tienen el carácter de contenidos particulares dentro de esta. Cabe decir que no son ideas que tenemos, sino ideas que somos. Más aún: precisamente porque son creencias radicalísimas se confunden para nosotros con la realidad misma -son nuestro mundo y nuestro ser--" (Ortega y Gasset 2006, 661s). 
KOSELLECK, Reinhart. Vergangene Zukunft: Zur Semantik, geschichtlicher Zeiten. Berlín: Suhrkamp, 1989

KOSELLECK, Reinhart. Von Sinn und Unsinn der Geschichte. Berlín: Suhrkamp, 2014.

MARÍAS, Julián. Obras, V. Madrid: Revista de Occidente, 1969.

MILL, John Stuart. A System of Logic: Ratiocinative and Inductive. Honolulu: University Press of the Pacific, 2002.

OAKESHOTT, Michael. Experience and its Modes. Cambridge: Cambridge University Press, 2015.

ORTEGA Y GASSET, José. Obras completas, V. Madrid: Fundación Ortega y Gasset / Taurus, 2006.

POLANYI, Michael. Personal Knowledge: Towards a Post-Critical Philosophy. Chicago: The University of Chicago Press, 1974.

RANKE, Leopold von. Geschichten der romanischen und germanischen Völker von 1494 bis 1514. Leipzig: Duncker \& Humblot, $1885^{3}$.

SCHILLER. Werke, I: Die Gedichte. Hamburgo: Standard Verlag, s.f.

TUCKER, Aviezer (Ed.). A Companion to the Philosophy of History and Historiography. Chichester (UK): Wiley-Blackwell, 2011.

VOLTAIRE. Essai sur les moeurs et l'esprit des nations et sur les principaux faits de l'bistoire depuis Charlemagne jusqu’à Louis XIII, II. París : Bordas, 1990.

WALSH, W. H. An Introduction to Philosophy of History. Londres: Hutchinson \& Co, 1977.

WINCH, Peter. The Idea of a Social Science, and its Relation to Philosophy. Londres: Routledge, 1991.

\section{(c)}

